\title{
Is immunising all patients with chronic lung disease in the community against influenza cost effective? Evidence from a general practice based clinical prospective cohort study in Utrecht, the Netherlands
}

\author{
E Hak, G A van Essen, E Buskens, W Stalman, R A de Melker
}

\begin{abstract}
Study objective-There is little information on the potential benefit of immunising all patients with chronic lung disease in the community against influenza. The clinical effectiveness and economic benefit was established of the influenza vaccination programme in a general practice based cohort of adult patients with chronic lung disease followed up during the 1995/96 influenza A epidemic.

Design-A prospective cohort study from October 1995 to March 1996.

Setting-The study was undertaken in the Utrecht General Practices Network with six large group practices, covering a total population of approximately 50000 patients in the Netherlands.
\end{abstract}

Patients-Computerised medical records of 1696 patients with chronic lung disease aged over 18 years with an indication for vaccination according to the Dutch GP guidelines were reviewed.

Main results-The overall attack rate of any complication, including all cause death, low respiratory tract infection, and acute cardiac disease was $15 \%$. Exacerbations of lung disease were most frequent (13\%). Death, pneumonia, and acute cardiac disease were mainly limited to patients $\geqslant 65$ years. No effectiveness of the immunisation programme could be established in patients $18-64$ years $(n=1066)$, after controlling for baseline prognosis in multivariable logistic regression analysis. In vaccinees $\geqslant 65$ years $(n=630)$, the occurrence of any complication was reduced by $50 \%$ (95\% CI 17, 70\%). The economic benefit was estimated at $£ 50$ per elderly vaccinee.

Conclusions-This study suggests that in the Netherlands immunisation of elderly patients with chronic lung disease against influenza is effective and cost-saving, hence these patients should be given high priority. More, preferably experimental, studies are needed to establish whether adult lung patients under 65 years in the community will also benefit from vaccination.

(F Epidemiol Community Health 1998;52:120-125)
Although annual influenza vaccination has been recommended to all patients with chronic pulmonary disease, ${ }^{1}$ immunisation rates remain low, particularly in patients under $65 .^{2-4}$ These low rates may only be partly the result of concerns about side effects, because many studies have shown no serious adverse events. ${ }^{5-8}$ Scepticism about the impact of influenza in non-institutionalised patients with chronic lung disease is more likely to play an important part. Currently, little information is available on influenza related mortality and morbidity in this group. ${ }^{9}$ Several studies have reported on the effectiveness of influenza vaccination, but most were confined to elderly subjects with or without chronic medical conditions. ${ }^{10-16}$ Only a few studies included younger adults, and none considered the effectiveness in patients with chronic lung disease alone. ${ }^{17-19}$ This apparent lack of evidence of the potential health and economic benefit resulting from immunising all patients with chronic lung disease in the community against influenza may explain the poor immunisation rates. ${ }^{9} 20$

We aimed to assess the clinical effectiveness of an influenza vaccination programme in preventing complications in adult patients with chronic pulmonary disease. We therefore prospectively followed up a general practice based cohort of patients with lung disease from the moment of vaccination until the end of the influenza A epidemic of 1995/96. Because an age based immunisation policy was recently introduced in the Netherlands, after many other countries, ${ }^{21}$ we considered its effectiveness in patients aged under and those aged over 65 years. Finally, we estimated direct costs of medical care associated with the influenza epidemic and immunisation programme.

\section{Methods}

SETTING AND STUDY SUBJECTS

The Utrecht University General Practices Network consists of six computerised group practices employing 23 general practitioners (GPs), and covering about 50000 patients living in the central part of the Netherlands. Since 1989, clinical diagnoses and drug prescriptions have been registered in the medical records using ICPC codes, ${ }^{22}$ according to the ICHPPC- 2 criteria, ${ }^{23}$ and ATC codes ${ }^{24}$ respectively. Anonymous data were stored in a central database. The initial step in the enrolment procedure consisted of a computerised search of 
Table 1 Baseline characteristics of study subjects $(n=1696)$. Numbers and percentages (\%) are given

\begin{tabular}{|c|c|c|c|}
\hline Characteristic & Non-vaccinees $(n=453)$ & Vaccinees $(n=1243)$ & $p$ Value \\
\hline \multicolumn{4}{|c|}{ Age category $(y)$} \\
\hline $18-64$ & $361(80)$ & $705(57)$ & \multirow[t]{2}{*}{$<0.001$} \\
\hline$\geqslant 65$ & $92(20)$ & $538(43)$ & \\
\hline \multicolumn{4}{|l|}{ Sex } \\
\hline Male & $268(59)$ & $621(50)$ & \multirow[t]{2}{*}{$<0.001$} \\
\hline Female & $185(41)$ & $622(50)$ & \\
\hline \multicolumn{4}{|c|}{ Health insurance } \\
\hline Private & $191(42)$ & $406(33)$ & \multirow[t]{2}{*}{$<0.001$} \\
\hline Sick fund ${ }^{\star}$ & $262(58)$ & $837(67)$ & \\
\hline \multicolumn{4}{|l|}{ Lung disease } \\
\hline Asthma† & $282(62)$ & $595(48)$ & \multirow[t]{2}{*}{$<0.001$} \\
\hline COPD $\ddagger$ & $171(38)$ & $648(52)$ & \\
\hline \multicolumn{4}{|c|}{ Cardiac comorbidity $\$$} \\
\hline No & $425(94)$ & $1074(86)$ & \multirow[t]{2}{*}{$<0.001$} \\
\hline Yes & $28(6)$ & $169(14)$ & \\
\hline \multicolumn{4}{|c|}{ Number of GP visits in previous 12 months } \\
\hline Low $(<3)$ & $383(85)$ & $923(74)$ & \multirow[t]{2}{*}{$<0.001$} \\
\hline $\operatorname{High}(\geqslant 3)$ & $70(15)$ & $320(26)$ & \\
\hline
\end{tabular}

* Compulsory for patients with income lower than $£ 21.50$. † In this category patients with pleurisy, other unspecified neoplasm lung, congenital anomalies, and other diseases of respiratory tract only are included $(n=23)$. $\ddagger$ Chronic obstructive pulmonary disease (in this category patients with neoplasm of lar/trac/bron/lung only are included, n=20). § ICPC codes K74-80, K82-84, K93 (see also data collection).

all potential patients with chronic lung disease in the period October 1993 to October 1995 using a software selection module. ${ }^{25}$ The search was based on the following diagnoses: COPD (chronic bronchitis/brochiectasis and emphysema), asthma, malignant and benign neoplasm of the bronchus/lung, tuberculosis, pleurisy, congenital anomalies, and other diseases of the respiratory system. In addition, patients with drug prescriptions from the ATCsubcategory R03 (adrenergics/other antiasthmatics) or with a "lung tag" indicating chronic lung disease only were selected. Participating GPs subsequently classified each initially selected patient as indicated for vaccination or not according to the guidelines of the Dutch College of General Practitioners. ${ }^{26}$ All selected high risk study subjects were invited for vaccination in writing. Patients under 18 years with asthma were not part of our study domain. Both risk of influenza related complications and vaccine effectiveness are different from that of adult patients with lung disease. ${ }^{927}$

INFLUENZA VACCINATION

Mass vaccination of patients who complied with the personal reminder took place in weeks 43 and 44 of 1995 . The trivalent subunit vaccine was based on $\mathrm{H} 3 \mathrm{~N} 2$ (A/Johannesburg/ 33/94-like), H1N1 (A/Singapore/6/86-like), and influenza B (B/Beijing/184/93-like) strains. ${ }^{28}$ All vaccinees were registered.
THE 1995/96 INFLUENZA A EPIDEMIC

The influenza epidemic started in week 46 (1995) and ended in week 10 (1996). ${ }^{28}$ The first and most important peak of influenza activity was observed in December/January and was associated with isolates of influenza $\mathrm{A}(\mathrm{H} 3 \mathrm{~N} 2)$, whereas the second peak in February was small and mainly associated with influenza $\mathrm{A}(\mathrm{H} 1 \mathrm{~N} 1)$ isolates. The vaccine composition largely matched viral strains isolated from clinical samples collected by the Dutch Sentinel Practice network. ${ }^{28}$

\section{DATA COLLECTION}

Baseline information extracted from the medical records included age, sex, type of health insurance, and the number of GP visits during the 12 months before vaccination. Medical history data included diagnoses of lung disease (see Setting and Study Subjects) and the following diagnoses of high risk cardiac comorbidity $^{26}$ : angina pectoris, myocardial infarction, other chronic ischaemic heart disease, heart failure, atrial fibrillation/flutter, paroxysmal tachycardia, ectopic beats, pulmonary heart disease, heart valve disease, other heart disease, and pulmonary embolism. Study outcomes were all cause death, exacerbation of pre-existent lung disease, pneumonia, congestive heart failure, acute myocardial infarction, and angina pectoris in week 46 (1995) to week 12 (1996). ${ }^{10-14} 2930$ Acute low respiratory tract illness (LRTI), including pneumonia and

Table 2 Outcome events (in \%) by age category and vaccination status

\begin{tabular}{|c|c|c|c|c|c|c|}
\hline \multirow[b]{2}{*}{ Outcome event } & \multicolumn{2}{|c|}{ 18-64 years * } & \multicolumn{2}{|c|}{$\geqslant 65$ yearst } & \multicolumn{2}{|c|}{ All ages } \\
\hline & Vact & $\mathrm{Vac}-$ & Vact & Vac- & Vact & $\mathrm{Vac}-$ \\
\hline LRTI/CD/death & 12.0 & 9.7 & $20.8 \ddagger$ & 31.5 & 15.8 & 14.1 \\
\hline \multicolumn{7}{|l|}{ Low respiratory tract illness (LRTI) } \\
\hline Exacerbation & 10.8 & 8.6 & 15.8 & 22.8 & 13.0 & 11.5 \\
\hline Pneumonia & 1.1 & 0.8 & 1.9 & 3.3 & 1.3 & 1.3 \\
\hline Total LRTI & 11.9 & 9.4 & 17.7 & 26.1 & 14.3 & 12.8 \\
\hline \multicolumn{7}{|l|}{ Cardiac disease (CD) } \\
\hline Congestive heart failure & 0.0 & 0.3 & 2.0 & 3.3 & 0.9 & 0.9 \\
\hline Angina pectoris & 0.0 & 0.0 & 0.6 & 1.1 & 0.2 & 0.2 \\
\hline Myocardial infarction & 0.1 & 0.0 & 0.2 & 1.1 & 0.2 & 0.2 \\
\hline Total CD & 0.1 & 0.3 & 2.8 & 5.4 & 1.3 & 1.3 \\
\hline
\end{tabular}

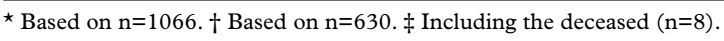


Table 3 Attack rates, crude and adjusted odds ratios (OR), and estimated effectiveness (adjusted \%) by age category $(n=1696)$

\begin{tabular}{|c|c|c|c|c|c|}
\hline Outcome event & $\begin{array}{l}\text { Attack rate } \\
(\%)\end{array}$ & $\begin{array}{l}\text { Vaccine } \\
\text { status }\end{array}$ & $\begin{array}{l}\text { Crude OR } \\
(95 \% \text { CI })\end{array}$ & $\begin{array}{l}\text { Adjusted } O R^{\star} \\
(95 \% \mathrm{CI})\end{array}$ & $\begin{array}{l}\text { Adjusted effectiveness * } \\
(95 \% \mathrm{CI})\end{array}$ \\
\hline \multicolumn{6}{|l|}{$18-64$ years $(n=1066)$} \\
\hline \multirow[t]{2}{*}{ LRTI $\ddagger / C D \$ /$ death } & 12.0 & Vact & $1.28(0.84,1.94)$ & $0.95(0.62,1.48)$ & $5(-48,38)$ \\
\hline & 9.7 & Vac- & & & \\
\hline \multirow[t]{2}{*}{ LRTI } & 11.9 & Vact & $1.30(0.85,1.98)$ & $0.97(0.63,1.52)$ & $3(-52,37)$ \\
\hline & 9.4 & Vac- & & & \\
\hline \multirow[t]{2}{*}{$\mathrm{CD}$} & 0.1 & Vact & NA & NA & NA \\
\hline & 0.3 & Vac- & & & \\
\hline \multicolumn{6}{|l|}{$\geqslant 65$ years $(n=630)$} \\
\hline \multirow[t]{2}{*}{ LRTI $\ddagger / C D \& /$ death } & 20.8 & Vact & $0.57(0.35,0.93)$ & $0.50(0.30,0.83)^{\star \star}$ & $50(17,70)$ \\
\hline & 31.5 & Vac- & & & \\
\hline \multirow[t]{2}{*}{ LRTI } & 17.7 & Vact & $0.61(0.36,1.01)$ & $0.54(0.32,0.93)^{\star \star \star \star}$ & $46(7,68)$ \\
\hline & 26.1 & Vac- & & & \\
\hline \multirow[t]{2}{*}{$\mathrm{CD}$} & 2.8 & Vact & $0.50(0.18,1.41)$ & $0.43(0.15,1.24)$ & $57(-24,85)$ \\
\hline & 5.4 & Vac- & & & \\
\hline
\end{tabular}

$\mathrm{NA}=$ not available. Numbers too small to construct a valid model. ${ }^{\star}$ Regression equation: outcome $=\beta 0+\beta 1^{\star}$ (vaccine status) + $\beta 2^{\star}$ ( $\mathrm{n}$, previous consultations) $+\beta 3^{\star}$ (underlying lung disease) $+\beta 4$ ( (cardiac comorbidity) $+95 \%$ confidence intervals. $\ddagger$ Low respiratory tract illness, including exacerbations and pneumonia. $\$$ Cardiac disease, including acute congestive heart failure, myocardial infarction and angina pectoris. ${ }^{\star \star}$ Adjusted Mantel-Haenszel weighted relative risk 0.62 (95\% CI 0.45, 0.86); variable GP visits dichotomised $(<3, \geqslant 3)$ for stratification. ${ }^{\star \star \star}$ Adjusted Mantel-Haenszel weighted relative risk $0.63(95 \% \mathrm{CI} 0.43,0.91)$.

exacerbations, was defined as the presence of one or more of the following signs/symptoms presented to the GP: (1) productive cough, (2) wheezy breathing or (3) increased dyspnoea in rest which led to the prescription of antibiotics, $\beta_{2}$ agonists or corticosteroids. Additional information included hospitalisation, length of hospital stay, and use of intensive care facilities. All medical data were checked in the medical records by a physician in April 1996.

\section{STATISTICAL ANALYSIS}

We dichotomised age into $18-64$ or $\geqslant 65$ years (retirement age $)^{1}$ and underlying lung disease into COPD or asthma. ${ }^{9}$ We combined the outcomes all cause death, acute LRTI, and cardiac disease (CD) to form the primary outcome measure. The two subsidiary outcome measures were any acute LRTI or CD. Univariate analyses were performed to compare vaccinees and non-vaccinees in baseline characteristics using $\chi^{2}$ tests for categorical variables and Student's $t$ test for continuous variables. Multivariable logistic regression modelling (with EGRET) was used to obtain adjusted estimates and their $95 \%$ confidence intervals of vaccine effectiveness. ${ }^{14}{ }^{141}$ In the first stage of constructing the model we defined the dependent variable as presence or absence of the primary outcome and the exposure term as vaccination status. We allowed for the potentially confounding variables age, sex, health insurance, lung disease defined as asthma or COPD, presence or absence of cardiac comorbidity, and number of GP visits in the previous 12 months and simultaneously added first order interaction terms of these variables with vaccination status and age. At this stage it became evident that the interaction term age by vaccination status contributed statistically significant to the model, whereas other interaction terms did not. We proceeded by constructing two separate models for both age categories separately. In the final models we only included those variables that substantially changes the estimate of vaccine effectiveness. Regression diagnostics, including distributional and residual plots, and assessment of outliers were used to assess the robustness of the models. Effective- ness was estimated using the formula: $(1-\mathrm{OR}) \times 100 \% .^{11}$ We calculated MantelHaenszel weighted relative risks (with EPIInfo) to verify estimates using odds ratios with frequent outcomes.

\section{ECONOMIC ANALYSIS}

We estimated direct costs of vaccination and combined average costs of hospital stay and use of intensive care facilities from a societal perspective. Net savings were estimated as follows: net savings= immunisation costs (including unit costs of vaccines and supplies, promotion, delivery, vaccination, and overhead)costs of medical care averted. The number of outcomes averted was calculated as follows: (N vaccinees $) \times$ (attack rate of outcomes among non-vaccinees $) \times$ (effectiveness). ${ }^{11}$ Immunisation costs were estimated at $£ 12.50$ per person, including supplies, promotion, delivery, vaccination, and overhead. The estimation was based on the total expenses of vaccination that could be claimed by GPs in 1995. Expenses were based on unit costs of vaccine $(£ 4.60)$ and delivery ( $£ 3.60$ ), and $£ 12.90$ for patients with private insurance, which equals $£ 4.30$ on average for all patients. Costs of expenses (or charges) were comparable with direct costs to society. Costs of hospital stay ( $£ 168 /$ day) and intensive care facilities ( $£ 821$ /day) were based on national data. ${ }^{32}$ To assess the effects of various estimates on the outcome of the economic analysis, an optimal and worst case scenario were established. We simultaneously varied estimates of effectiveness, proportion of patients needing medical care, and median length of hospital stay over a plausible range of plus or minus 20 per cent.

\section{Results}

The overall influenza vaccination rate in the 1696 study subjects was $73 \%$. Age specific immunisation rates were 66 (18-64 years) and $85 \%$ ( $\geqslant 65$ years). At baseline, vaccinees were older (57 compared with 47 years, $t$ value 10.5, $\mathrm{p}<0.001$ ), more often female, and insured through the Sick Fund than non-vaccinees. Also, COPD, cardiac comorbidity, and a high 
GP visiting rate were more common among vaccinees (table 1 ).

Overall, the attack rate of any complication was $15 \%$, mainly due to LRTI (14\%). Exacerbations of underlying lung disease were most frequently observed $(12.7 \%)$. The occurrence of death $(0.5 \%)$, CD $(1.3 \%)$, and pneumonia $(1.3 \%)$ was less frequent. The recorded primary cause of death was cardiac heart failure (3), pneumonia (2), pneumothorax, cachexia, and ileus $(n=8)$.

In patients aged 18-64 years, the attack rate of any complication in vaccinees was slightly higher than in non-vaccinees (table 2). Acute $\mathrm{CD}$ and pneumonia were rarely observed, and no deaths occurred. In contrast, the occurrence of any complication in the elderly ( $\geqslant 65$ years) was substantially higher, although less common in vaccinees than in non-vaccinees (21 compared with $32 \%$ ).

Table 3 shows the results of the multivariable analyses. In patients aged 18-64 years, no effectiveness of the immunisation programme in reducing the occurrence of any complication could be established, after adjustment for the prognostic confounding variables underlying lung disease, cardiac comorbidity, and number of GP visits (adjusted OR 0.95, 95\% CI 0.62, 1.48 , table 3 ). The inclusion of the other baseline variables age, sex, and health insurance did not confound the association between outcomes and vaccination status. Vaccination in the elderly ( $\geqslant 65$ years) was associated with a substantial reduction of the occurrence of any complication ( $50 \%)$, any acute LRTI $(46 \%)$, or CD (57\%, not statistically significant) after adjustments. In patients with cardiac comorbidity $(n=197)$, the effectiveness in preventing acute CD amounted even to $80 \%$ (95\% CI 32 to $98 \%$, data not shown).

In all, the hospitalisation rate was $1.8 \%$. In $90 \%$ of hospitalised patients, one or more of the following risk factors was present: age over 65 years, COPD, cardiac comorbidity, or a high GP visiting rate. As vaccine effectiveness could only be demonstrated in patients $\geqslant 65$ years, we limited economic analyses to these subjects (table 4). The hospitalisation rate in elderly patients (including the deceased) with LRTI was $9.2 \%$ and $45 \%$ for elderly with CD. Median hospital stay due to LRTI was 10 days (range 5-20 days) with $1.7 \%$ in intensive care, while for CD it was 14 days (range 7-60 days) with $15 \%$ in intensive care. In the scenario analyses, we varied effectiveness in preventing

Table 4 Estimated direct costs (savings) associated with influenza vaccination per 100 vaccinated patients with chronic pulmonary disease ( $\geqslant 65$ years) in the Netherlands

\begin{tabular}{ll}
\hline Outcome variable & Estimated costs (in $£)$ \\
\hline Vaccination $(£ 12.50$ per vaccination) & 1250 \\
Medical care avoided for respiratory disease & 1848 \\
Hospital stay & 328 \\
Intensive care & 3259 \\
Medical care avoided for cardiac disease & 821 \\
Hospital stay & 5007 \\
Intensive care &
\end{tabular}

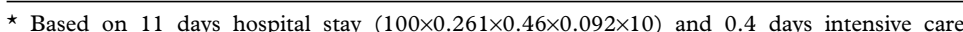
$(100 \times 0.261 \times 0.46 \times 0.015 \times 2)$ for LRTI per 100 vaccinees avoided. $†$ Based on 19.4 days hospital stay $(100 \times 0.054 \times 0.57 \times 0.45 \times 14)$ and 1 day intensive care $(100 \times 0.054 \times 0.57 \times 0.15 \times 2)$ for $\mathrm{CD}$ per 100 vaccinees avoided.
LRTI from 26 to $66 \%$ and CD from 37 to $77 \%$. Hospitalisation rates due to LRTI were varied from 7.4 to $11 \%$ and CD from 36 to $54 \%$, while median stay in hospital was varied from 8 to 12 days and from 12 to 16 days, respectively. After subtracting the mean vaccination costs, we estimated the net savings to be $£ 50$ (range from $£ 16$ to $£ 101$ ) per elderly vaccinee.

\section{Discussion}

The findings in this study suggest that influenza vaccination is effective and costsaving in elderly patients with lung disease, but not in those aged under 65 years. However, some issues need to be considered. Confounding by indication is one of the important threats when studying intervention effects using an observational design. As shown in our study, vaccinees were at higher risk of developing complications than non-vaccinees, which could have led to an underestimation of the vaccine effectiveness. This confounding may therefore have obscured a potential benefit in the younger age group. Nevertheless, the immunisation rate of $66 \%$ was high compared with most other vaccination studies, ${ }^{10-14}$ which probably reduces serious differences in baseline prognosis. Also, the study population was homogeneous with regard to indication criteria and the prevalence of lung disease (36 of 1000) was comparable with Dutch general practice morbidity registration data $(30-40$ of 1000). ${ }^{26}{ }^{33}$ Furthermore, we adjusted for some important prognostic confounding variables. The variable underlying lung disease was given by subdividing patients into asthmatic patients and COPD patients in accordance with other studies. ${ }^{9}{ }^{34}$ Misclassification of lung disease was most probably very limited, because participating GPs were extensively trained in classifying lung patients according to ICHPPC-2 criteria. Health seeking behaviour and seriousness of disease were also controlled for by the number of previous GP visits. ${ }^{14}$ Nevertheless, we could only adjust for known differences in vaccinees and non-vaccinees. Complete comparability of vaccinees and non-vaccinees with regard to the prognosis of developing influenza related complications can only be guaranteed in a randomised placebo controlled trial.

We could not obtain valid information on previous vaccinations. Some reports suggest a reduced effectiveness if patients are vaccinated for the first time. ${ }^{16}{ }^{17}$ As our GPs have been immunising lung patients against influenza since the early nineties, it is probable that most vaccinees had been vaccinated more often.

Another possible limitation, like in all other large effectiveness studies, ${ }^{10-151718}$ includes the absence of laboratory confirmation of influenza. A sensitive and non-specific definition of clinical outcome may lead to an underestimation of the effectiveness. ${ }^{14}$ Although it has not been reported yet, specificity of outcome definitions may be higher in the elderly when compared with the younger age group. This might have contributed to the established differences in effectiveness. Our finding of no effectiveness in younger adults is in agreement 
with an earlier report by Wiselka and colleagues $^{3}$ who could not establish vaccine effectiveness in preventing exacerbations in asthmatic patients aged 6 to 56 years during the $1989 / 90$ epidemic. Most exacerbations in their study subjects were indeed thought to be caused by viruses other than influenza $\mathrm{A}$. Beasley et $a l^{27}$ concluded that only in one third of severe exacerbations in asthmatic patients aged $15-56$ years could a viral agent be identified. The potential impact of an immunisation programme on the overall reduction of complications may be at stake when influenza is not the causal agent. Two other cost-benefit studies indicated no financial benefit from immunising patients under 65 with various medical conditions. ${ }^{19}{ }^{35}$ The authors attributed this to low death and hospitalisation rates in the younger age group during an influenza epidemic. We observed no deaths in patients under 65 and hospitalisation rates were 3.2 times lower in this group.

The inclusion of acute lung and heart disease as it presents to the GP in the primary outcome measure may be considered an important advantage of this study. The burden of illness could mainly be attributed to exacerbations of pre-existing lung disease (13\%), whereas a minority of patients (2\%) was hospitalised. Studies in which hospitalisation and death are the primary end points may suffer from more serious selection bias, because hospitalisation is mainly limited to patients with severe medical conditions as shown in our study.

The fact that all deceased persons were vaccinated reflects a high immunisation rate in the elderly subjects $(85 \%)$. We were not able to confirm influenza as the primary cause of death, hence inferences about vaccination status and mortality are difficult. ${ }^{36}$ Our age specific death rate of $1.3 \%$ in the elderly was substantially lower than reported by Fleming et $a l^{14}$ (3.0\% in high risk elderly) and comparable to rates reported by Nichol et $a l^{10}$ who included mostly healthy non-institutionalised elderly. Immunisation rates in these studies were lower than in our study (10\% and $58 \%$, respectively).

The estimated vaccine effectiveness of $50 \%$ in the elderly is in accordance with a recently published large meta-analysis, ${ }^{13}$ but net savings seemed to be higher than reported earlier. ${ }^{10-12}$ As indirect costs resulting from work loss are less important in the elderly, we only calculated direct costs. ${ }^{10}$ Furthermore, we decided not to add costs resulting from consultations for side effects, because only few such consultations occurred in this study. Possible savings from the reduced number of GP consultations and drug use were even not taken into account. Accordingly, our estimates of net savings may be considered conservative.

Recently, Tirimanna and colleagues ${ }^{34}$ showed that more than half the patients with asthma or COPD were not even known to the GP. Although screening on lung function was not part of this study, it is probable that elderly patients with unknown lung disease could also benefit from vaccination. An age based vaccination policy may increase the likelihood of reaching all elderly patients with known and
KEY POINTS

- The 1995/96 influenza epidemic was associated with a high attack rate of complications $(15 \%)$ in patients with chronic lung disease.

- Exacerbations of pre-existent lung disease were among the most frequent complications (13\%).

- In the Netherlands, the influenza vaccination seemed to be cost-saving in patients with chronic lung disease aged over 65 years.

- This study gives no evidence for vaccine effectiveness in adult patients with chronic lung disease under 65 years.

unknown high risk medical conditions in the community. ${ }^{21}$

Our study suggests that in the Netherlands the immunisation of elderly patients with chronic lung disease against influenza is effective and cost-saving. A population based strategy should be developed so that these patients can be identified and immunised efficiently. ${ }^{25}$ More, preferably experimental studies are needed to establish whether adult patients with lung disease under 65 years should be given priority as well.

We thank D E Grobbee, Professor of Epidemiology and Public Health, and N Masurel, Professor Emeritus of Virology, for useful comments on the manuscript. We are also grateful to $\mathrm{Mr} \mathrm{A}$ ful comments on the manuscript. We are also grateful to
Lodder for assistance on the statistical part of the study.

Utrecht General Practices Network group HAM Asbreuk, JG
Utrourt of the study. Utrecht General Practices Network group HAM Asbreuk, JG
Blankestijn, JG Blommestein, JF Bolderink, GJA Daggelders, Blankestijn, JG Blommestein, JF Bolderink, GJA Daggelders,
MEL van Dillen, WH Eizenga, MM de Groot, EFHM MEL van Dillen, WH Eizenga, MM de Groot, EFHM
Hendrickx, R Hirsch, HHG de Jong, JMA Juffermans, ME Hendrickx, R Hirsch, HHG de Jong, JMA Juffermans, ME
Numans, HM Pieters, CD Rijkens, FH Rutten, BE van der Numans, HM Pieters, CD Rijkens, FH Rutten, BE van der
Snoek BE, Y Stoutenbeek, L Truijens, W Stalman, MW Van den Broek, NJ de Wit, WLG van Zijl.

Funding: this study was financially supported by the Dutch Council of the Sick Fund

Conflicts of interest: none.

1 Nicholson KG, Snacken R, Palache AM. Influenza immunization policies in Europe and the United States. Vaccine 1995;13:365-9.

2 Meynaar IA, Wout JW van't, Vandenbroucke JP, Furth R van. Use of influenza vaccine in The Netherlands. BMF 1991;303:508.

3 Wiselka MJ, Kent J, Nicholson KG, Stern M. Influenza and asthma. Lancet 1992;339:367-8.

4 Fiebach N, Beckett W. Prevention of respiratory infections in adults. Arch Intern Med 1994;154:2545-57.

5 Nichol KL, Margolis KL, Lind A, et al. Side effects associated with influenza vaccination in healthy working adults. A randomised, placebo-controlled trial. Arch Intern Med 1996;156:1546-50.

6 Govaert Th ME, Dinant GJ, Aretz K, Masurel N, Sprenger MJW, Knottnerus JA. Adverse reactions to influenza vaccine in elderly people: randomised double blind placebo vaccine in elderly people: randomised do

7 Albazzaz MK, Harvey JE, Grilli EA, Caul EO. Subunit influenza vaccination in adults with asthma: effect on cliniinfluenza vaccination in adults with asthma: effect on clini-
cal state, airwayreactivity, and antibody response. BMF cal state, airwayreac

8 Stenius-Aarniala B, Huttunen JK, Pyhälä R, et al. Lack of clinical exacerbations in adults with chronic asthma after immunisation with killed influenza virus. Chest 1986;89: $786-9$.

9 Rothbarth PH, Kempen BM, Sprenger MJW. Sense and nonsense of influenza vaccination in asthma and chronic obstructive pulmonary disease. Am f Resp Crit Care Med 1995; 151:1682-6.

10 Nichol KL, Margolis KL, Wuorenma J, Sternberg T von. The efficacy and cost-effectiveness of vaccination against influenza among elderly persons in the community. N Engl f Med 1994;331:778-84.

11 Mullooly JP, Bennett MD, Hornbrook MC, et al. Influenza vaccination programs for elderly persons: cost-effectiveness in a health maintenance organization. Ann Intern Med in a health main

12 McBean AM, Babish JD, Warren JL. The impact and cost of influenza in the elderly. Arch Intern Med 1993;153: 2105-11. 
13 Gross PA, Hermogenes AW, Sacks HS, Lau J, Levandowski RA. The efficacy of influenza vaccine in elderly persons. A
meta-analysis and review of the literature. Ann Intern Med 1995;123:518-27.

14 Flemming DM, Watson JM, Nicholas S, Smith GE, Swan AV. Study on the effectiveness of influenza vaccination in the elderly in the epidemic of 1989-90 using a general practice database. Epidemiol Infect 1995;115:581-9.

15 Ohmit SE, Monto AS. Influenza vaccine effectiveness in preventing hospitalization among the elderly during
influenza type A and type B seasons. Int f Epidemiol 1995; 24:1240-8.

16 Govaert ThME, Thijs CTMCN, Masurel N, Sprenger MJW, Dinant GJ, Knottnerus JA. The efficacy of influenza vaccination in elderly individuals. A randomized doubleblind placebo-controlled trial. $\mathcal{F A M A}$ 1994;272:1661-5.

17 Ahmed Ah, Nicholson KG, Nguyen-Van-Tam. Reduction in mortality associated with influenza vaccine during 1989-90 mortality associated with influenza

18 Fedson DS, Wadja A, Nicol JP, Hammond GW, Kaiser DL, Roos LL. Clinical effectiveness of influenza vaccination in Roos LL. Clinical effectiveness of influe
Manitoba. $7 A M A$ 1993;270:1956-61

19 Riddiough MA, Sisk JE, Bell JC. Influenza vaccination. Cost-effectiveness and public policy. $\mathcal{F} A M A$ 1983;249: 3189-95.

20 Ong ELC. Influenza and asthma. Lancet 1992;339:367.

21 Fedson DS, Hannoun C, Leese J, et al. Influenza vaccination in 18 developed countries, 1980-1992. Vaccine 1995;13 623-7.

22 Lamberts $\mathrm{H}$, Wood $\mathrm{M}$, eds. ICPC. International classification of primary care. Oxford: Oxford University Press, 1987.

23 Classification committee of WONCA. ICHPPC-2 defined. International classification of health problems in primary care. Oxford: Oxford University Press, 1983.

24 Anonymus. Anatomical Therapeutic Chemical (ATC) classification index. Oslo: WHO Collaborating Centre for Drug Statistics Methodology, 1996.

25 Hak E, Hermens RPMG van, Essen GA van, Kuyvenhoven MM, De Melker RA. Population-based prevention of
influenza in Dutch general practice. Br f Gen Pract influenza in Din
26 Essen GA van, Sorgedrager YCG, Salemink GW, Govaert ThME, Hoogen JPH van den, Laan JR van der. NH-Standaard Influenza en influenzavaccinatie. (NHG guidelines Influenza and influenza vaccination). Huisarts Wet 1993;36:342-6. (With abstract in English).

27 Beasley R, Coleman ED, Hermon Y, Holst PE, O'Donell $T V$, Tobias M. Viral respiratory tract infections and exacerbations of asthma in adult patients. Thorax 1988;43:67983.

28 Claas ECJ, Jong JC de, Bartelds AIM, Rimmelzwaan GF, Wijngaarden JK van, Osterhaus ADME. Influenza in het seizoen 1995/96; vaccinsamenstelling voor het seizoen $1996 / 97$. (Influenza in the 1995/96 season; vaccine composition for the 1996/97 season). Ned Tijdschr Geneesk 1996;140:2047-50. (With abstract in English).

29 Connolly AM, Salmon RL, Williams DH. What are the complications of influenza and can they be prevented? Experience from the 1989 epidemic of H3N2 influenza A in general practice. BMF 1993;306:1452-4.

30 Bainton D, Jones GR, Hole D. Influenza and ischaemic heart disease- a possible trigger for acute myocardial heart disease- a possible trigger for
infarction? Int $\mathcal{f}$ Epidemiol 1978;7:231-9.

31 Hosmer DW, Lemeshow S. Applied logistic regression. New York: John Wiley, 1989.

32 Rutten FPH, Ineveld BM van, Ommen R van, Hout BA an, Huijsman R. Kostenberekening bij gezondheidszorgonderzoek. Richtlijnen voor de praktijk. (Calculating costs in health care research. Guidelines for practical use) Utrecht: Jan Van Arkel, 1993. (In Dutch).

33 Lamberts H, Brouwer HJ, Mohrs J. Reason for encounter-, episode- and proces-oriented standard output from the Transition project. Amsterdam: Department of General Practice, University of Amsterdam, 1991.

34 Tirimanna PRS, Schayck CP van, Otter JJ den, et al. Prevalence of asthma and COPD in general practice in 1992: Has it changed since 1977? Br f Gen Pract 1996;46:27781 .

35 Perez-Tirse J, Gross PA. Review of cost-benefit analyses of influenza vaccine. PharmacoEconomics 1992;2:198-206.

36 Fleming DM, Cross KW. Respiratory syncitial virus or influenza? Lancet 1993;342:1507-9. 